\title{
DIRETRIZES DE PROJETO PARA A REFORMA E AMPLIAÇÃO DO EDIFÍCIO DO “PROJETO ALEGRIA DE SER" EM ÁLVARES MACHADO - SP
}

\author{
Beatriz Siquieri Oliveira, Mayara Pissutti Albano. \\ Universidade do Oeste Paulista - UNOESTE, Faculdade de Engenharias e Arquitetura e Urbanismo, \\ Presidente Prudente, SP. E-mail: ma.albano@unoeste.br
}

\begin{abstract}
RESUMO
No Brasil, tanto a Constituição Federal de 1988, quanto o Estatuto da Criança e do Adolescente de 1990, determinam como dever da família, em primeiro lugar, da comunidade, da sociedade em geral e do Estado assegurar às crianças e adolescentes os seus direitos fundamentais, incluindo, entre eles, o direito à convivência familiar e comunitária. Diante deste contexto, a temática do ambiente escolar para a infância vem ganhando cada vez mais espaço e tendo reconhecida sua importância na discussão sobre o desenvolvimento infantil. Entretanto, as características físicas destes ambientes continuam geralmente sendo negligenciadas no planejamento de espaços infantis coletivos. Baseado nesse contexto a presente pesquisa tem como objetivo desenvolver estudos que embasem um possível projeto de reforma e ampliação do edifício do Projeto Alegria de Ser em Álvares Machado, bem como dar diretrizes projetuais para o mesmo. Para o cumprimento desse objetivo, serão realizadas pesquisas bibliográficas, documentais e de campo.
\end{abstract}

Palavras-chave: Edifício escolar, Arquitetura escolar, Projeto Alegria de Ser, Diretrizes Projetuais, Álvares Machado - SP.

\section{DESIGN GUIDELINES FOR THE REFORM AND EXPANSION OF THE BUILDING OF THE "PROJETO ALEGRIA DE SER" IN ALVARES MACHADO-SP}

\begin{abstract}
In Brazil, both the 1988 Federal Constitution and 1990 Statute of the Child and Adolescent determine how duty of the family, first and foremost, the community, the society and the State to ensure children and adolescents their fundamental rights including, among them, the right to family and community life. In this context, the theme of the school environment for children is gaining more and more space and having recognized its importance in discussion on child development. However, the physical characteristics of these environments are still often being neglected in planning children's collective spaces. Based on this context, this research aims to develop studies that could support a possible project of renovation and expansion of the Projeto Alegria de Ser building in Alvares Machado and give projective guidelines for the same. For the fulfilment of that goal, will be carried out documentary and bibliographic research field.

Keywords: School Building, School Architecture, Projeto Alegria de Ser, Project Guidelines, Álvares Machado-SP.
\end{abstract}




\section{INTRODUÇÃO}

Segundo a Constituição Federal de 1988, e o Estatuto da Criança e do Adolescente de 1990, é dever da família, da comunidade, da sociedade em geral e do Estado assegurar às crianças e adolescentes os seus direitos fundamentais, dentre os quais estão o direito à convivência familiar e comunitária, explicitado da seguinte forma: "toda criança ou adolescente tem direito a ser criado e educado no seio da sua família e, excepcionalmente, em família substituta". (Art. 19, Lei no 8.069/1990).

Observando o contexto social, marcado pelo conjunto de carências e pelas condições em que os brasileiros vivem e trabalham, os cidadãos pertencentes às camadas sociais mais baixas, em geral, têm os seus direitos sociais suprimidos e os buscam nos centros de atendimento destinados a serviços sociais público como alternativas para suas dificuldades. (VERONESE, 1994).

Diante deste contexto, a temática do ambiente escolar para a infância vem ganhando cada vez mais espaço e tem sua importância reconhecida na discussão sobre o desenvolvimento infantil. Entretanto, os ambientes públicos onde tais atividades são desenvolvidas possuem, muitas vezes, características físicas deficientes e/ou insuficientes para atender as crianças e funcionários usuários do espaço.

O Projeto Alegria de Ser é um projeto social e educacional que oferece atividades complementares às escolares no período em que as crianças ficariam possivelmente desassistidas. O projeto atende crianças e adolescentes em situação de vulnerabilidade social, proporcionando benefícios físicos, emocionais, sociais, sendo assim fortalecendo os vínculos familiares e comunitários.

O projeto Alegria de Ser necessita de um ambiente adequado às necessidades de nutrição, recreação, educação e saúde dos usuários, com ambientes que estimulem o desenvolvimento das potencialidades da criança, adequados a sua idade e ritmo individual de crescimento. $O$ projeto arquitetônico de reforma e adequação do espaço, quando realizado, deverá buscará respeitar o universo infantojuvenil, dando importância aos primeiros anos de vida, proporcionando, por meio de ambientes adequados, um bom desenvolvimento e aprendizagem.

Com isso, o objetivo norteador do presente trabalho, está focado em estudos que subsidiarão um possível futuro projeto de reforma e ampliação do edifício onde está instalado o Projeto Alegria de Ser na cidade de Álvares Machado - SP, resultando em diretrizes projetuais para o mesmo, a fim de que o espaço onde funciona o referido projeto se torne um ambiente adequado ao desenvolvimento das crianças atendidas.

\section{METODOLOGIA}

A metodologia utilizada nesta pesquisa foi desenvolvida através da investigação qualitativa, utilizando-se de levantamento bibliográfico, de pesquisa documental, de levantamentos físicos arquitetônicos in locu no edifício que abriga o referido projeto.

Primeiramente foi realizado levantamento bibliográfico em livros e periódicos com as principais obras referentes aos assuntos trabalhados, visando embasar as diretrizes projetuais que foram realizadas posteriormente. Num segundo momento realizou-se pesquisas documentais junto à Prefeitura Municipal de Alvares Machado - SP, mantenedora do projeto social. A análise documental é, segundo Lüdke e André (1986, p.38), uma "uma técnica valiosa de abordagem de dados qualitativos, seja complementando informações obtidas por outras técnicas, seja desvelando aspectos novos de um tema ou problema". Posteriormente foram realizados levantamentos in locu, que compreendem medições, levantamentos fotográficos e observação direta, a fim de se obter dados concretos da situação do edifício, das problemáticas e das potencialidades que serviram de base para as diretrizes projetuais. 


\section{O EDIFÍCIO ESCOLAR - ARQUITETURA E EDUCAÇÃO}

Etimologicamente o termo "arquitetura" vem da junção das palavras gregas "arché", que significa "primeiro" ou "principal", e tékton, que possui o significado de "construção". Desde os primórdios da humanidade as pessoas realizam construções com funções diversas como: proteção, demonstração de poder de reis e deuses e produção de arte, entre outras funções. A arquitetura trata da organização do espaço e de seus elementos, como organização, estética e ordenamento de componentes.

Kanitz (2000) argumenta que as salas de aula de padrão usual não passam de "um monte de cadeiras voltadas para um quadro-negro e uma mesa de professor bem imponente em cima de um tablado." (KANITZ, 2000, p. 21), criticando o padrão usual das salas de aulas atualmente.

Segundo Kowaltowski (2011, p. 11), "o edifício escolar deve ser analisado como resultado da expressão cultural de uma comunidade, por refletir e expressar aspectos que vão além da sua materialidade". Sendo assim nota-se que a escola é essencial no aspecto social e cultural de uma cidade e do país como um todo.

Buffa e Pinto (2002) ponderam que:

As ideias pedagógicas e sua assimilação na prática escolar são articuladas a diversos modos de projetar e construir prédios escolares. As idéias pedagógicas e sua assimilação na prática escolar têm um dinamismo próprio, tanto quanto têm sua própria evolução as concepções arquitetônicas e sua influência no projeto e construção de edifícios escolares. [...] Às vezes, educadores e arquitetos estão próximos, há uma clara concepção pedagógica a influenciar a conceito arquitetônico. [...] Outras vezes, percebe-se um maior distanciamento entre eles, talvez pela ausência de uma proposta pedagógica explícita, ou talvez porque falte ao arquiteto que projeta a escola uma sensibilidade pelas questões de ensino (Buffa; Pinto, 2002, p.154).

Quando passamos a entender que é preciso haver uma boa relação entre o aluno e o ambiente escolar, tem-se o papel da arquitetura na educação. Duarte (1999, p. 114) ressalta que:

0 projeto arquitetônico de uma instituição de ensino deve ser subordinado, em primeiro lugar, à criança. Pois, é para ela que se faz um colégio e não para os professores, assim como se faz um hospital para os doentes e não para os médicos. Ele afirma que as escolas deveriam ser alegres e acolhedoras, não podiam, portanto, assemelhar-se a prisões com muros altos e janelas inacessíveis, realidade de alguns colégios brasileiros.

De acordo com Kowaltowski (2011) cabe ao arquiteto o conhecimento dos aspectos pedagógicos, uma vez que eles refletem o tipo de atividade que as escolas vão desenvolver, e são esses elementos que definem o programa de necessidades de cada edificação escolar.

Segundo Azevedo (2002), a produção de uma arquitetura de qualidade depende diretamente do nível de adequação e desempenho de seus ambientes, assim considerando aspectos ambientais, de ordem técnica, funcional e estética, consequentemente, todos esses aspectos afetam o bem estar do usuário.

Kowaltowski (2011, p.111) pondera que "A arquitetura escolar e a satisfação do usuário em relação á qualidade do ambiente estão diretamente ligadas ao conforto ambiental, que inclui os aspectos térmico, visual, acústico e funcional proporcionados pelos espaços externos e internos". O usuário do espaço deve ser elemento ativo e receber atenção relativas às suas necessidades, para que o resultado do projeto as satisfaça.

O Projeto Alegria de Ser, necessita de novas soluções arquitetônicas, proporcionando um ambiente estimulante para o desenvolvimento das crianças e jovens que frequentam e realizam as atividades propostas, visto que o edifício existente não o faz. 


\section{PROJETO ALEGRIA DE SER}

O município de Álvares Machado situa-se no interior do estado de São Paulo e abriga o Projeto Alegria de Ser. O projeto sócioeducacional foi inaugurado em 1999 e está instalado em um edifício que não foi construído para este fim, portanto, apresenta inúmeras deficiências no cumprimento da função que exerce.

O Projeto Alegria de Ser atende crianças encaminhadas pela rede de proteção social especial, egressos de trabalho infantil, crianças reconduzidas ao convívio familiar, após medida protetiva de acolhimento, crianças e adolescentes encaminhadas pelo Conselho Tutelar, por fragilização de vínculos familiares, crianças e adolescentes cujas famílias são beneficiárias de programas de baixa renda, ou com dificuldade para manter a família.

O terreno, onde o projeto está implantado localiza-se na região central de Álvares Machado, em uma das principais avenidas da cidade. Possui $837,50 \mathrm{~m}^{2}$ de área, e seu único acesso se faz pela Avenida das Américas (figura 1).

Figura 01 - Planta de situação do terreno no centro da cidade.

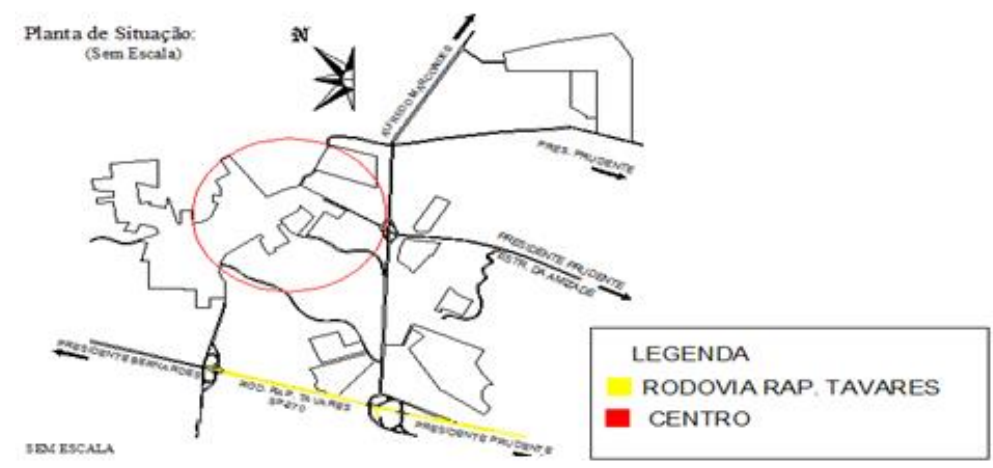

Fonte: Prefeitura de Álvares Machado, 2015. Modificado: Autora, 2016.

O edifício foi construído pela Prefeitura Municipal, e não houve preocupação com o acesso de pessoas com mobilidade reduzida, e nem projeto arquitetônico que considerasse a importância do espaço lúdico para o desenvolvimento infantil. O edifício conta apenas com duas salas de aula, um banheiro feminino e um masculino, cozinha, refeitório, depósito, e uma sala que é usada como coordenação e área para os professores (Figura 2).

Figura 02. Implantação

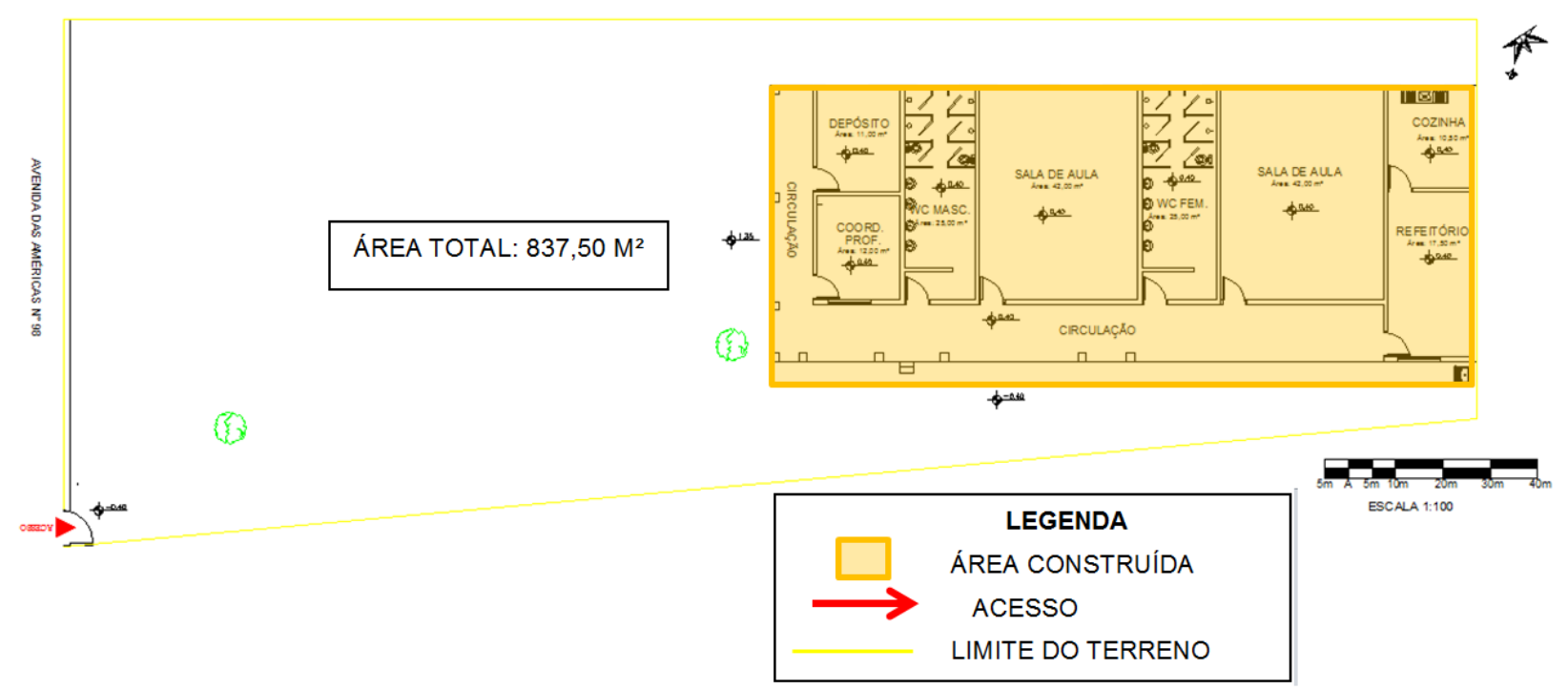

Fonte: autores, 2016. 
O refeitório é muito pequeno (Figura 3), as mesas e os bancos estão em péssimas condições, segundo relatos dos funcionários, como não cabem todas as crianças para fazerem as refeições todas juntas, é feito um rodizio, e uma quantidade de crianças fazem suas refeições, depois as outras.

Figura 03. Refeitório

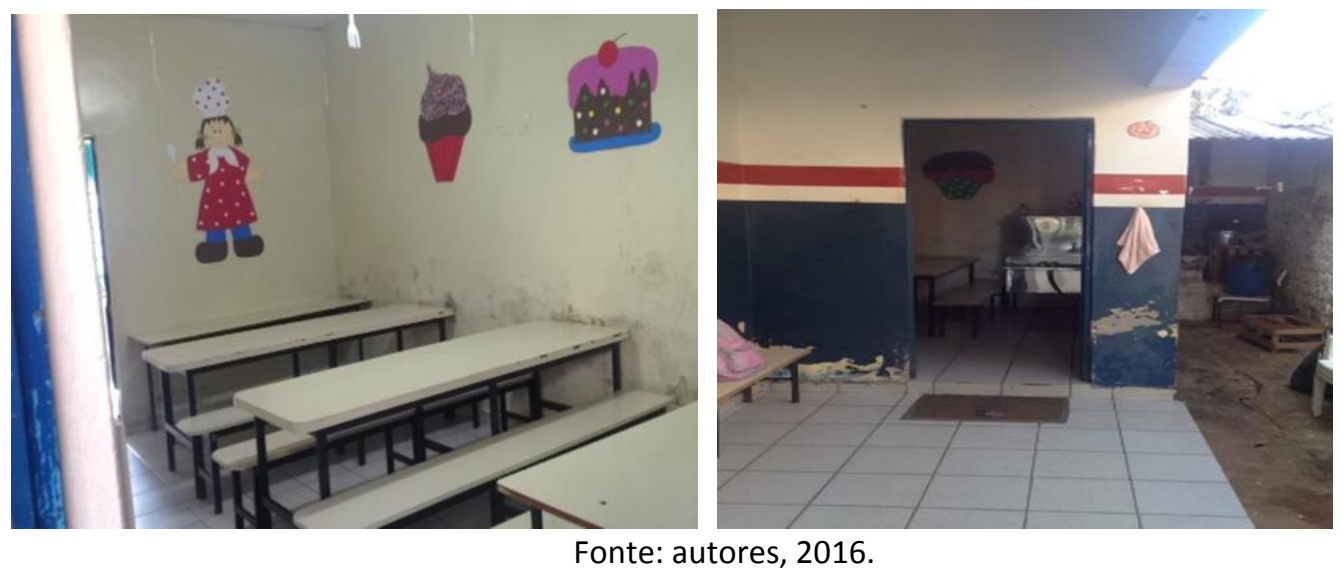

O único depósito do edificío é inadequado (Figura 4 a), pois além de muito pequeno, as mercadorias ficam todas misturadas, limpeza, com alimentação entre outras coisas armazenadas ali. A cozinha é muito pequena (Figura 4 b), para atender as necessidades do local e não está em boas condições.

Figura 04. Depósito e Cozinha
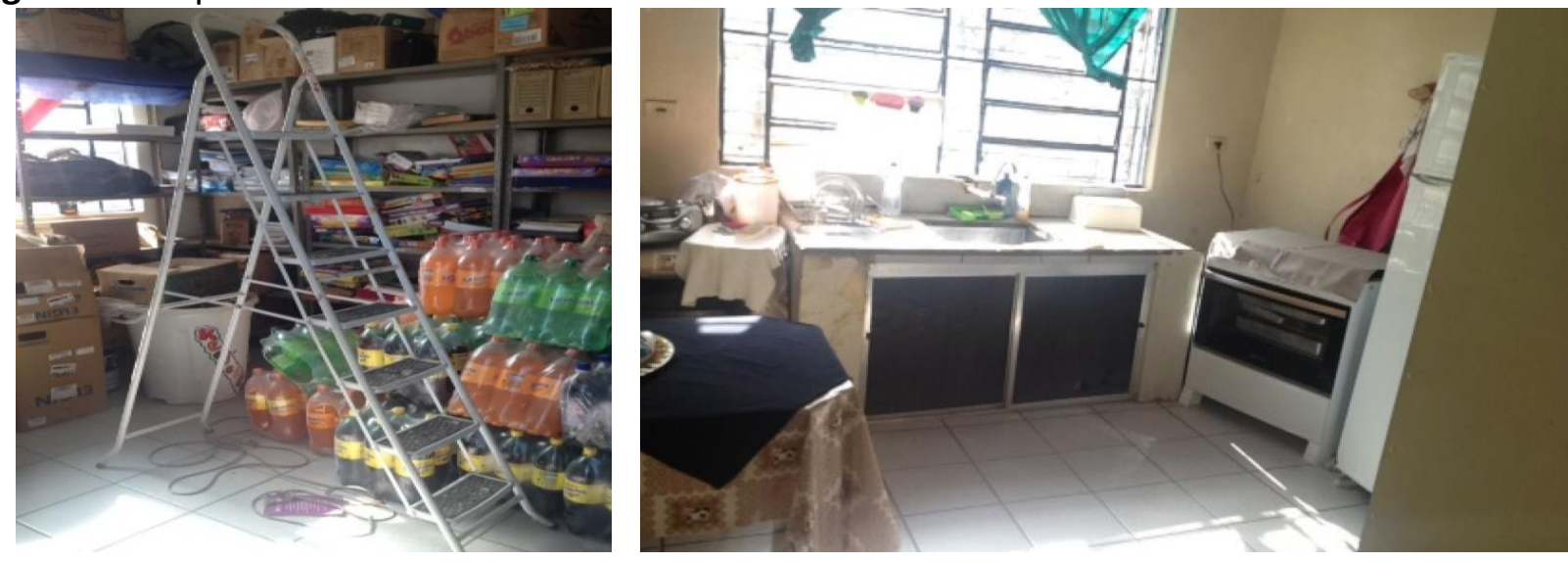

Fonte: autores, 2016.

O edifício só possui dois banheiros, um feminino e um masculino. Não há banheiros para os funcionários, eles utilizam os mesmos que os alunos. Os banheiros também estão um pouco degradados.

Foi possível notar, durante a pesquisa de campo, que o edifício não possui condições adequadas para exercer sua função e, para tanto se faz necessária uma reforma e ampliação do mesmo, cujas diretrizes projetuais serão apresentadas a seguir.

\section{DIRETRIZES PROJETUAIS}

As diretrizes do projeto seguirão as normas da Fundação para o Desenvolvimento da Educação - FDE. O Fundo Nacional de Desenvolvimento da Educação - FNDE, autarquia federal criada pela Lei no 5.537, de 21 de novembro de 1968, e alterada pelo Decreto-Lei $n=872$, de 15 de 
setembro de 1969, é responsável pela execução de políticas educacionais do Ministério da Educação e Cultura (MEC), relacionadas a educação básica, prestando auxílio financeiro e técnico aos municípios e executando ações que contribuem para uma educação de qualidade. (BRASIL, 2016).

Tendo em vista a situação existente no local, foram traçados as diretrizes projetuais, que visam o melhor desenvolvimento do projeto, sendo elas:

- O uso dos catálogos da FDE para nortear os dimensionamentos do programa de necessidades;

- Flexibilidade: projeto capaz de se adequar a diferentes propostas pedagógicas, por meio de um espaço versátil, promovendo integração e conectividade entre as áreas internas e externas.

- Acessível: podendo atender a todas as crianças, portadoras de necessidades especiais ou não. As circulações devem seguir as normas de acessibilidade da NBR 90/50, já que a preexistência não tem nenhuma acessibilidade.

- Lúdico: apto para estimular os sentidos e despertar a criatividade das crianças.

\section{CONSIDERAÇÕES FINAIS}

A partir das análises realizadas é possível notar que a execução deste trabalho se faz necessária, devido à importância do Projeto Alegria de Ser para as crianças e adolescentes do munícipio. A edificação existente para desempenho desta função, não articula de uma forma eficiente a função de promover o convívio e integração social, não cumpre de forma adequada a demanda do seu território, causando deficiência na proposta de que esta deve servir de referência para o fortalecimento de vínculos familiares e desenvolvimento social da população.

O Projeto realizado sob as diretrizes apresentadas deve reforçar e buscar promover integração social, flexibilidade espacial para desenvolvimento de atividades socioeducativas, tornando-se referência tanto arquitetônica como urbana, e desenvolvimento sociocultural. Com essa ampliação e reforma atendendo assim, um número maior de crianças e adolescentes do munícipio,

\section{REFERÊNCIAS}

AZEVEDO, Giselle Arteiro Nielsen. Arquitetura Escolar e Educação: Um Modelo Conceitual de Abordagem Interacionista. Tese de Doutorado. Rio de Janeiro: FAU/UFRJ, 2002.

BRASIL. Constituição Federal, 1988.

BRASIL. FDE - $\quad$ Catálogos Técnicos. Disponível em: < http://catalogotecnico.fde.sp.gov.br/meu site/index.html>. Acessado em: 15.maio.2016.

BUFFA, Ester; PINTO, Gelson de Almeida. Arquitetura e Educação: Organização do espaço e propostas pedagógicas dos grupos escolas paulistas, 1893/1971. São Carlos: Brasília: EdUFSCar, INEP, 2002.

DUARTE, R. B. Recomendações para o projeto e execução de edifícios de alvenaria estrutural. Porto Alegre: ANICER, 1999.

KANITZ, Stephen. Volta às aulas. Veja São Paulo, SP, n. 1634, fev. 2000. Disponível em: <http://www.kanitz.com.br/://.>. Acesso em: 05 mar. 2016.

KOWALTOWSKI, Doris C. C. K. Arquitetura Escolar: o projeto do ambiente de ensino. São Paulo: Oficina de Textos, 2011. 
LUDKE, Menga e ANDRÉ, Marli. E. D. A. Pesquisa em Educação: Abordagens qualitativas. São Paulo: EPU, 1986.

VERONESE, Josiane Rose Petry. Acesso à justiça: A Defesa dos Interesses Difusos da Criança e do Adolescente-ficção ou Realidade?. Florianópolis, SC: UFSC, 1994. 